\title{
Cimicifuga Racemosa
}

\section{Agarwal T*}

Assistant professor, Banasthali vidhypeeth, India

${ }^{*}$ Corresponding author: Dr. Teena Agrawal, Assistant professor, Banasthali

Vidhypeeth, Niwai, India, Tel: +91-9680724243; Email: tagrawal02@gmail.com

\section{Mini Review}

Volume 2 Issue 6

Received Date: August 22, 2018

Published Date: September 03, 2018

\begin{abstract}
Cimicifuga Racemosa is one of the most important of all the indigenous remedies. Its range of action is quite extensive; it has been quite thoroughly proven; the clinical experience with it is already large; and it has great possibilities for future development.
\end{abstract}

Keywords: Herbal medicines of the classical world; Temperate Himalayas; Rich Woodlands; TM; ATM

\section{Introduction}

Herbal medicines of the classical world, is still a matter of the great dilemma, the exact origin of the herbal medicine is still unknown, but it is supposed that the Mediterranean basin is the somewhat the exact origin the herbs for the treatment, the TM and the ATM are the main medicines which are used in the several utilization due to its efficacy and simple easy uses and the less toxic natures of the herbs in comparison to the synthetic drugs , here in this review article we are presenting some of the aspects of the herbal medicines of the Cimicifuga Racemosa BP of the ranunculaceae family. The genus is distributed in the temperate Himalayas, rich woodlands [1-20].

The plant parts of the Cimifuga racemosa is the rhizome which issued for gather several purposes. The main Principle is the cimicifugin, resin, fats, starch, gum, tannic acid, Gallic acid, volatile oil, the roots is alternatives, stomachic, aphrodisiac, diuretic, and antispasmodic, its action on the heart, and the circulation system is equal to the digitalis, some time the inspired muscular action resembles with the ergot, in small doses it increase the action of the genial system and the other systems. In toxic doses it works as the irritant ants, dilate the pupil, headaches, nervous tremor, violent delirium, giddiness, nausea, depression of pulses [21-30].

The plant is given in the chronic muscular rheumatisms, lumba-torticolis, intercostals neuralgia, Pleurodenia, headache due to the fatigue. Cimifugin is given for the uterine contraction and the other purposes.

\section{Conclusion}

This is the overall small genus, and we have presented the small facts, it is informative for the students of the Pharmacology and the peoples of the biosciences. The folk medicines are the main medicines which are used by the tribal peoples by the long time, they are based on the thousands years experiences of the tribal peoples over the generations, the experiences was passed from the one generation to the another by the means of the talk $s$ and the other means of the knowledge transmission. Well the plant is full of the toxic elements, and so careful investigations are need for the proper analysis of the plants [31-48]. 


\section{Journal of Natural \& Ayurvedic Medicine}

\section{References}

1. Schoepf (1785) Materia medica Americana.

2. Barton BS (1801) Collections for an Essay Towards a Materia Medica of the United Statespart 2, pp: 9.

3. Hand WM (1820) House Surgeon and Physician, pp: 236.

4. Bigelow (1822) A Treatise on the Materia Medica, A Sequel to the Pharm. of the US, pp: 125.

5. Medical Recorder (1823).

6. Barton WP (1827) Outlines of Lectures on Materia Medica and Botany, pp: 94.

7. Philadelphia Monthly (1827) Journal of Medicine and Surgery.

8. Ewell J (1827) The Medical Companion, or Family Physician. $7^{\text {th }}$ (Edn.), pp: 748.

9. Rafinesque (1828) Medical Flora of the United States, 1: 85 .

10. Edwards and Vavasseur (1829) A Manual of Materia Medica and Pharmacy, (translation of Togne and Durand), pp: 339.

11. (1830) Pharmacopoeia of the United States, Philadelphia, pp: 31.

12. (1830) Pharmacopoeia of the United States, New York, pp: 27.

13. Rafinesque (1830) Medical Flora of the United States, 2: 201.

14. Smith E (1830) The Botanic Physician, pp: 425.

15. Coxe (1831) The American Dispensatory. 9th (Edn.), pp: 21.

16. (1832) American Journal of Medical Sciences, 9: 310.

17. (1832) An Improved System of Botanic Medicine, 2: 183-300.

18. Beach (1833) The American Practice of Medicine 3: 30

19. Barton WPC (1833) Prodome of a Work to Aid in the Teaching of the Vegetable Materia Medica, pp: 74.
20. Wood, Bache (1833) Dispensatory of the United States of America. 1 ${ }^{\text {st }}$ (Edn.), pp: 196.

21. (1834) American Journal of Pharmacy, pp: 14.

22. (1835) The Sick Man's Friend, Sanborn, pp: 40.

23. (1839) American Medical Intelligencer, 2: 296.

24. (1839) Boston Medical and Surgical Journal, pp. 65, 126.

25. (1840) American Journal of Medical Sciences, 9: 281.

26. (1840) New York Journal of Medicine and Surgery, pp: 191.

27. (1840) Pharmacopoeia of the United States, pp: 18.

28. (1841) The Botanic Medical Reformer, 1: 206.

29. (1842) American Journal of Medical Sciences, pp: 288.

30. (1842) A Treatise of the Botanic Theory and practice of Medicine, worthy, pp: 582.

31. (1843) American Journal of Medical Sciences, 5: 61.

32. (1843) General Therapeutics and Materia Medica, Dunglison. $2^{\text {nd }}($ Edn.), 2: 194.

33. (1844) New York Philosophical Journal

34. (1844) American Journal of Pharmacy, pp: 1.

35. Reese (1844) Medicines, Their Uses and Mode of Administration, Neligan, pp: 373.

36. Griffith (1847) Medical Botany. Philadelphia, Lea and Blanchard, pp: 92.

37. Royle (1847) Materia Medica and Therapeutics, pp: 246.

38. (1847) The Botanico Medical Reference Book, pp: 545.

39. (1848) Ives Report to the American Medical Association, pp: 351.

40. A Dispensatory, or Commentary, on the Pharmacopoeias of Great Britain and the United States, Christison, $2^{\text {nd }}$ (Edn.), pp: 366.

41. Lee (1848) The Medicinal Plants of New York, pp: 6.

42. Cincinnati (1849) Eclectic Medical Journal, pp: 1. 


\section{Journal of Natural \& Ayurvedic Medicine}

43. Porcher (1849) The Indigenous Medicinal Plants of South Carolina, (Report of American Medical Association), pp: 686.

44. Kost (1849) Elements of Materia Medica and Therapeutics, pp: 232.

45. (1850) Pharmacopoeia of the United States, pp: 21.
46. (1850) Medicinal Plants of the United States, Clapp (Report American Medical Association), pp: 723.

47. (1851) New Remedies, Dunglison. 6 $6^{\text {th }}$ (Edn.), pp: 212.

48. King, Newton (1852) The Eclectic Dispensatory of the United States of America, pp: 250.

\section{(c) (i)}

